\title{
THE POSSIBLE EFFECT OF THE PROTECTION OF PERSONAL INFORMATION ACT 4 OF 2013 ON ORGAN AND TISSUE DONATIONS
}

\section{Introduction}

Organ donation for purposes of a transplant is an altruistic act that lends itself to the ethical principle of beneficence. Available evidence indicates that in the transplant process information or data sharing is of the utmost importance. The Constitution of the Republic of South Africa, 1996 (hereinafter "the Constitution") and other legislative frameworks like the National Health Act 61 of 2003 (hereinafter "the NHA"), facilitates participation in support of this principle. Section 12(2) of the Constitution states that "Everyone has the right to bodily and psychological integrity, which includes the right - ... (b) to security in and control over their body; and (c) not to be subjected to medical or scientific experiments without informed consent." Section 27(1) and (2) provide that everyone has the right to have access to health care services... The same section immediately prompts the state to "take reasonable legislative and other measures, within its available resources, to achieve the progressive realisation of each of these rights".

The NHA in sections 14-17 applies a safeguard on how the principle of beneficence in respect of organ donations should be achieved. These sections address the issues of confidentiality, access to and the protection of health records. The guarantees in the Constitution and the NHA are not absolute but may be limited in one way or another, especially in cases where the donor is declared brain dead and therefore deceased. In such a case the Protection of Personal Information Act 4 of 2013 (hereinafter "the POPI Act") does make provision for instances where the protection of personal information may be limited. Although it is feared that the POPI Act might negatively influence the organ donation process, an analysis of the Act and its possible influence on the transplantation scenario seems unfounded if a few precautionary measures are put in place.

\section{The purpose of the POPI Act and consent}

The purpose of the POPI Act is to promote the protection of personal information processed by public and private bodies. The Act sets out the minimum requirements for the processing of personal information. The Act also envisages an Information Regulator to be established who should exercise his or her powers according to the Act itself but also in terms of the Promotion of Access to Information Act, 2000 (hereinafter "PAIA Act") (The 
National Assembly approved the appointment of members of the Information Regulator on 7 September 2016). The POPI Act further explains the issuing of Codes of Conduct to provide for the protection of personal information in certain sectors like the transplant environment for example.

Concisely, the main purpose of the Act is thus to protect a person's constitutional right to privacy (s 14 of the Constitution). "[T]he right to privacy includes a right to protection against the unlawful collection, retention, dissemination and use of personal information" (Preamble of the POPI Act). It means the Act is there to ensure that all South African institutions conduct themselves in a responsible manner when collecting, processing, storing and sharing personal information, by holding them accountable should they abuse or compromise this information in any way (See Monthy "The Popping of POPI" 2015 15(6) Without Prejudice 86-87; Omarjee "Is your Business POPI Compliant" April 2015 FINWEEK 38).

The POPI Act was signed into law in November 2013. On 11 April 2014 the following sections of the Act became effective: Section 1 which deals with the definitions; Part A of Chapter 5 which deals with the establishment of the Information Regulator; section 112 which deals with the fact that the Minister may make regulations relating to the establishment of the Regulator; and section 113 dealing with the procedures on drafting regulations by the Minister or the Regulator. Once section 114 is enacted, all processing of personal information must conform to the requirements of the Act within one year after that date. The whole POPI Act is therefore not effective yet, and because of that, it is still unclear what the effect of the Act will be on the transplant environment (See Steenekamp "Protection of Personal Information Act, No 4 of 2013" https://www.saica.co.za/Technical/LegalandGovernance/(accessed 2016-08-04)).

The Act protects each individual's personal information and gives one the ability to exercise control over when and how one chooses to share information which "means any voluntary, specific and informed expression of will in terms of which permission is given for the processing of personal information" (s 1 of the POPI Act). The type and extent of information one chooses to share must be collected for valid reasons and there must be transparency and accountability on how the information will be used (s 4 and 5 of the POPI Act). One must also be given a choice to have the information removed and destroyed if so wished (s 14(4) of the POPI Act). There must be adequate measures and controls in place to track access and prevent unauthorised people, even within the same working place, from accessing the information. An individual's data (information) must be captured correctly and it must be safeguarded from theft (s 19 of the POPI Act). The legal framework therefore, provides that information may only be shared if the individual consents. However, the POPI Act is not consent driven, meaning it does not explain in detail how consent should be given; therefore it is more a weighing up of rights and interests. If you want to process personal information, the Act provides the conditions on how to do it lawfully (s 9, 10 and 11 of the POPI Act). Examples of "personal information" could include, but are not limited to, the following: an identity number, phone number(s), email addresses, physical address, gender, race, criminal record, 
educational information and so forth (s 1 of the POPI Act). The Act defines a "unique identifier" to be data that "uniquely identifies that data subject [person] in relation to that responsible party [person working with the information]" ( $\mathrm{s} 1$ of the POPI Act). It is important to remember that each person should protect his or her own personal information as the Act cannot protect a person if that person does not take care to protect his or her information themselves.

The Act is applicable to natural persons and legal entities and by implication to hospitals. A hospital should therefore, protect all information about their employees, independent contractors, suppliers, vendors, service providers as well as patients.

\section{Legislation and guidelines as well as the POPI Act in health care}

The stipulations in the POPI Act prevail unless another Act protects the personal information of an individual more extensively (s 3(2)(b) of the POPI Act). In a health context it means the POPI Act does not replace the NHA (s 14-17) or the Ethical Rules of Conduct for Practitioners Registered under the Health Professions Act 56 of 1974 (GN R717 in GG of 2006-08-04, s 13) or the Health Professions Council of South Africa's (HPCSA) existing guidance on safeguarding confidential patient data or even the Medical Protection Society's Guide on medical records in South Africa (www.mps.group.org/za-mla (accessed 2017-05-15)). The POPI Act must be read in conjunction with the existing legislation and guidelines.

The HPCSA's Ethical Rules state in section 13 that a practitioner shall divulge information regarding a patient only in terms of a statutory provision; at the instruction of a court of law; or where it is justified in the public interest (authors' own emphasis). It could be argued that an organ or tissue donation is in the public interest as it is saving lives. The second part of section 13 states that a practitioner shall only divulge information regarding a deceased patient, with the written consent of his or her next-of-kin or the executor of such deceased patient's estate. This requirement could be a hurdle in the transplant context as time is always an issue. Not only are there costs involved in keeping a brain dead patient on machines, organs should be harvested soon after death to increase the chances of a better outcome for the recipient. If the physician has to get the written consent of the next-of-kin before information can be given to a transplant coordinator, valuable time can be lost. The Ethical Rules do not address organ donations directly, but it could be argued that the public interest requirement in the first part of section 13 in the transplant context, trumps the second part requiring written consent.

The HPCSA's Guidelines for Good Practice in the Health Care Professions: General ethical guidelines for the healthcare professional, (Booklet 1, Pretoria, May 2008) state under the core values and standards required of healthcare practitioners the following: 
"2.3.8 Confidentiality: Health care practitioners should treat personal or private information as confidential in professional relationships with patients unless overriding reasons confer a moral or legal right to disclose."

It seems as if the above clause is in line with the POPI Act, but it could also be argued, once again, that there is a moral obligation on practitioners to provide information on possible organ or tissue donors. If the potential donor is dead to provide their families' information to transplant coordinators considering that organ/tissue donations are in the interest of society as a whole.

Another HPCSA document: Confidentiality: Protection and Providing Information (www.hpcsa.co.za/downloads/conduct_ethics/rules/generic_ethi cal.../booklet_10pdf (accessed 2016-06-30)) contains all the key elements about ensuring confidentiality and the disclosure of confidential information in different scenarios. The relevant part in the transplant context is section 9.5.1 (HPCSA Booklet 10) which states:

"Health care practitioners still have an obligation to keep personal information confidential after a patient dies. The extent to which confidential information may be disclosed after a patient's death will depend upon the circumstances (authors' own emphasis). These include the nature of the information, whether that information is already public knowledge or can be anonymised, and the intended use to which the information will be put. Health care practitioners should also consider whether the disclosure of information may cause distress

to, or be of benefit to, the patient's partner or family."

In other words, if a person is brain dead, it could be seen as a valid reason to disclose the information on his/her file, as the intended use of the information is to save other lives.

Apart from complete compliance with the POPI Act once effective, as well as strict adherence to the requirements of the NHA and the documents in terms of the HPCSA, and the MPS, the POPI Act should also be read and interpreted in conjunction with the PAIA Act, which gives effect to the constitutional right of access to any information held by the state and any information that is held by another person that is required for the exercise or protection of any rights.

The organ and tissue donation process functions completely on the giving out of personal information of the deceased as well as the personal information of his or her family members to a third party, namely the transplant coordinator. All of the above pieces of legislation and the HPCSA documents should therefore, be consulted and complied with in the transplant context.

When human tissue is donated, the process is a bit different from organ donations, as the deceased need not be brain dead but any death has the potential for a donation of bones and skin. Role players like mortuaries and funeral undertakers can also become part of the tissue donation process. When there are other people apart from the deceased involved in the donation chain, it becomes even more prudent to comply with current legislation and in future, it will be compulsory to also comply with the POPI Act. To get better clarity on the effect of the POPI Act on organ and tissue 
transplantations, it is meaningful to distinguish between: (a) the donation of organs from dead donors, (b) living organ donors and (c) tissue donations.

\section{The organ (kidneys, lungs, liver, pancreas, heart) donation process linked to the POPI Act}

The POPI Act only applies to living people. In other words once the person has died, the Act has no application anymore concerning the personal information of the deceased and it seems unnecessary to discuss the POPI Act in this regard, but the Act still applies to the people (next-of-kin) who gave consent for an organ donation (s 3 of the POPI Act). These persons' personal information, which is usually in the records of the deceased, is still protected by the Act even though they are not patients of the hospital.

\section{Donations of deceased persons}

Section 62 of the NHA determines that any person competent to make a will (16 years) may in the will or in a document signed by him or her and at least two competent witnesses (14 years or older) or in an oral statement made in the presence of at least two competent witnesses, donate his or her body or any specified tissue thereof to be used after his or her death for any purposes provided for in the Act (s 64 of the NHA). In the absence of a donation made by the person him or herself, the spouse, partner, major child, parent, guardian, major brother or sister (authors' own emphasis) of the deceased (in the specific order mentioned) may after the death of the person donate the body or any specific tissue of that person (s 62(2) of the $\mathrm{NHA}$ ). If none of the people mentioned can be located, the Director-General of the Department of Health may after all the prescribed steps have been taken to locate a family member or partner, donate any specific tissue on behalf of the deceased (s 62(3) of the NHA). The donated organs obtained from deceased persons for the purpose of transplantation may only be used in the prescribed manner (s 61 of the NHA). Therefore, although the hospitals' patient is dead, there is still personal information on the file of the patient concerning other living persons and the Act applies to these people. The privacy of the family members of the deceased must be protected, but it is inevitable that their contact details could be used as described below. The NHA is silent on how the listed people (above) should be contacted in order to consent to an organ donation.

\section{General practice concerning dead donors in South Africa}

Once a person is declared brain dead (s 1 of the NHA defines "death" as brain dead) the hospital staff, if educated in this sphere, will inform a transplant coordinator. They (the hospital) will give the information of the next-of-kin of the deceased to the coordinator who will then approach such to ask whether organs from the dead body of their loved one could be used for transplantation purposes. 
The application of the POPI Act is relevant in the sense that in order for the coordinator to approach family members for a possible donation, the hospital unit has to use personal information they have concerning the nextof-kin of the deceased. Usually, when a person is hospitalised, he or she has to provide the particulars of a next-of-kin who could be contacted should the hospital find a need for the family members to come to the hospital. The ideal situation is that the family member accompanying the patient to the hospital, should give consent that their information may be on the patient's file and that the information may be used when necessary.

This information of the family (who is still alive) is personal information and therefore it is protected by the POPI Act. The hospital staff should therefore, comply with the Act in providing the personal particulars of family members of a deceased to the transplant coordinator. This action of supplying the information would be legal if the family member consented thereto on the admission of the deceased. The information should be used in a lawful and reasonable manner (s 9 of the POPI Act) provided the purpose for which it is used is adequate, relevant and not excessive (s 10 of the POPI Act). Because the hospital staff work under the authority of the hospital management, they will also need to comply with section 20 of the POPI Act, which states that the authority under which the information is used, should be aware that personal information is given out. If hospitals had a routine referral policy, according to which all possible donors are referred to a transplant coordinator, they could give out the personal particulars of a possible donor without the hospital management being aware thereof, as they would be protected under section 20(b) of the POPI Act. This section gives an operator [ICU staff] the right to use personal information "in the course of the proper performance of their duties". Unfortunately, routine referrals are not a policy in South African hospitals yet. If routine referrals could become official policy in hospitals, it would assist in complying with the POPI Act more accurately.

This "using" of the personal information of family members of the prospective donor could also be seen as legal from another angle. The POPI Act makes provision for the usage of personal information to protect or pursue a "legitimate interest" (s 11(1)(f) of the POPI ACT). It is not clear at this stage what constitutes a legitimate interest, as there is neither a definition nor any case law to clarify the concept. As argued above, an organ donation could be a "legitimate interest" as the donation may spare the life of a patient waiting for a transplantable organ; it is in society's interest to save lives and thus could be a legitimate interest.

Any person who has or gives out personal information is obliged to restrict the processing or use of the information for the purpose for which it was gathered (s 15(1) of the POPI Act). In other words, ICU staff cannot after they have given the information to the transplant coordinator, use that same information for their own interest, such as advertising their cupcake business. The coordinator must also only use the information legitimately and not for personal purposes.

Should the personal information be given to someone who wants to do research on organ transplantations, the information of the donor and the 
information of the family members who gave consent for the donation, should be de-identified, in other words, there should be no way to re-identify the people (see s 1 of the POPI Act, definition of de-identify). Personal information may not be processed without notifying the data subject, in this instance, the family, unless the data has been rendered non-identifiable or it is in the public interest to do so.

Thus, there seems to be no problem to comply with the POPI Act if information of family members on the file of the deceased, is given to a transplant coordinator who approaches the family members in the hospital for a possible organ donation. It seems more complicated if the ICU staff supply the information to a coordinator and the coordinator then telephones the family to ask for a possible organ donation. In such a case the family would have a right to ask where the coordinator got their personal information. In such an instance, it seems that the family could raise an objection against the usage of their personal information but if the above arguments stand that their information is used for a legitimate interest the coordinator and the hospital should be safe. Generally it seems to be a better approach to ask family members of a brain dead patient in the hospital for consent to harvest usable organs for transplantation.

\section{$42 \quad$ Living donors}

Section 55 of the NHA requires written consent from a living donor. Only a kidney and a part of a liver can currently be donated by a living donor in South Africa. Although it is practice to use only blood-related living organ donors, there is no specific piece of legislation with this requirement. If the living donor is not blood-related to the recipient but an altruistic donor, permission from the Minister of Health is necessary before the donation can take place.

\section{Living donations: The general practice in South African hospitals}

Once a willing living donor comes forward, tests are done on both the donor and the recipient to see whether they are medically compatible. Files will be opened for both the donor and the recipient with a lot of personal identifiers. It is important to know that the patient or donor has a right to know what information concerning them is recorded on file (s 18 of the POPI Act). As both the donor and the recipient are alive, the POPI Act will be applicable to both these parties' personal information. If the transplant takes place, the information of both donor and recipient should be stored as required by law as both then become patients of a treating physician (s 14(1) of the POPI Act); see also HPCSA Booklet 14: Guidelines on the keeping of patient records, Pretoria May 2008)). If the donor is medically not compatible with the recipient of the organ, his or her personal information should not be retained by the hospital longer than necessary. It should be destroyed or deidentified (s 14 of the POPI Act). If a prospective donor feels his or her personal information has been misused a complaint may be directed in writing to the Regulator. 


\section{Tissue (skin, bone and corneas) donation and the POPI Act}

According to section 54 of the NHA, only an authorised institution (see the Regulations relating to Tissue Banks No 35099 in GG of 2012-03-02) may amongst others acquire, use or supply the body of a deceased person. The Regulations in terms of the NHA explain how human tissue may be preserved, processed, stored, labelled and packed to be used for transplantation purposes (s 1 of the Regulations). Human tissue must also be donated after informed consent has been given in the same way as organs as discussed above (s 62 of the NHA).

Once a person has died in any manner, not being specifically brain dead, the hospital, or even the mortuary or a funeral undertaker can notify a transplant coordinator that consent has been given for a tissue donation. The tissue bank will arrange for the harvesting of the tissue, which in most instances is skin, bone and corneas. Because the body from which the tissue is taken is dead, the POPI Act is not applicable to the personal particulars of the deceased. It is usually the family of the deceased that will give consent for a tissue donation and their particulars are protected by the POPI Act. In order to get hold of family members for consent to a tissue donation, the mortuary, or funeral home have to use personal identifiers to give to transplant coordinators in order to contact the relevant people. Thus, the question arises whether according to the POPI Act, mortuaries and funeral homes have a right to give this personal information to a transplant coordinator. Because there is no case law to rely on at this moment, it might be better for funeral homes and mortuaries to design a Code of Conduct in these situations (POPI Chapter 7).

People getting a call from a transplant coordinator concerning the tissue of their deceased loved one at a funeral home, are usually distressed by the fact that they are asked for a donation. The first question they have is normally where the coordinator got their personal information. It seems as if according to the POPI Act it would be unlawful for the funeral home or mortuary to give out the personal information of family members of a deceased to a transplant coordinator. A possible solution seems to be that the tissue bank should supply the mortuary or funeral home with leaflets explaining the tissue donation process as well as how and when the tissue of a deceased could be used. These leaflets could then be given to the family members of the deceased. They could then call the coordinator themselves, or they could give their consent to the owner of the mortuary or funeral home to use their personal information by giving it to a transplant coordinator.

A Code of Conduct in this regard might go a long way. A Code of Conduct may not be less restrictive than the Act and it must include all the conditions for the legal processing of personal information, namely: accountability, processing limitation; purpose specification; further processing limitation; information quality; openness; security safeguards and data subject participation (s 4 of the POPI Act). A Code of Conduct is issued by the Regulator but it is designed by the people involved in the specific field where 
it will be applied (s 60 and 61 of the POPI Act). The Regulator must give notice in the Government Gazette that the issuing of a Code of Conduct is being considered and submissions or comments concerning the Code should be invited (s 61 of the POPI Act). In other words, it might benefit the transplant society or even tissue banks to develop a code in relation to the POPI Act as soon as possible to safeguard them from being caught in the dark should the POPI Act be enacted.

\section{Conclusion}

The POPI Act should not be a hindrance to the donation process as long as the role players do not misuse personal information, but even in such an instance, the Act provides for remedial action. A better solution for the uncertainty concerning the usage of the personal information of family members of donors could be that the transplant society or tissue banks should draw up their own Codes of Conduct concerning the use of information for transplantation or research purposes. Codes of Conduct are provided for in the POPI Act. The purpose of a tailor-made Code of Conduct is to give responsible parties in a particular sector, such as the transplant sector, clearer guidance on the acquisition and processing of personal information. The Code can be developed by any interest group, but if it does not comply with the Act, the Information Regulator may revoke it.

Magda Slabbert

University of South Africa (UNISA), Pretoria

and

Patricia Molusi

University of South Africa (UNISA), Pretoria 